\title{
Collision Statistics: A Study in Toronto Road Safety
}

AUTHORS: Kevin Leung, Jerry lu, Gabriel Gelgor and Arbri Halili

SCHOOL: Earl Haig Secondary School in Toronto, Ontario

\section{Abstract}

This study set out to determine the major causes of vehicle collisions in the City of Toronto and to propose solutions to the issue. We have made use of Toronto Open Data to gather statistics on wellbeing demographics, traffic, economics, and collisions. Data was analyzed and it was determined that six neighbourhoods deviated from the normal ratio of collisions to road volume. We researched these six neighbourhoods and determined that most accidents occur in commercial areas and the least accidents happen in residential areas. Residential areas are not areas where large amounts of people collect daily, but commercial areas are, and the high amounts of pedestrian movement within commercial areas coupled with vehicle traffic likely increases the chance of collisions. Vehicle accidents can be reduced in several ways, such as producing more PSAs, enforcing jaywalk prevention, reducing speeding and employing advents in driving technology such as driverless cars.

\section{Key Words}

Commute, Neighbourhoods, Accidents, Safety, Toronto

\section{Introduction}

On average in Toronto, Ontario, roughly 50,000 people are involved in potentially avoidable vehicle accidents every year. Traffic collisions are a problem that affects everyone. In a metropolitan city like Toronto, driving is essential, and traffic collisions are a major issue. In 2013, there were 57 homicides and 63 traffic fatalities, suggesting that traffic is a comparable issue to major crimes. We decided to study collision statistics to unearth potential causes for accidents in specific areas, and potential changes to help improve road safety. For this study, we were given access to tools such as Dell Statistica and the City of Toronto's open data database.

Through the assumption that the number of drivers will directly affect the number of traffic accidents that occur, we hypothesize that areas with greater traffic volume will have the greatest number of accidents. From our research, we aim to find the causes of these accidents and formulate suggestions for solutions.

\section{Methods}

We obtained data sets from Toronto Open Data for use in this study. These data sets were the Wellbeing Economics [2], Demographics [1], and Traffic [3] data sets. The primary tool we used was Dell Statistica. In Dell Statistica, we merged and organized all the data sets into one. We created a ratio and a graph of total collisions versus road volume. Road volume is defined as the number of vehicles per 24 hours. We chose six outliers as this sample size is small enough to be manageable and large enough to be meaningful. Our final decision was based on their distance from the trend line of our graph and from neighbouring points. These deviations from the trend were also visible on a table of ratios, based on distance from the mean value and neighbouring values.

Using these six neighbourhoods, we determined "negative" and "positive" outliers, where negative refers to neighbourhoods with a high ratio of collisions to road volume, and positive refers to neighbourhoods with a low ratio. We assume lower means safer, so we use positive and negative to describe the potential safety of a neighbourhood, where positive is more safe and negative is less safe. We analyzed common factors between each set of outliers. These include area, size of local population, road length in kilometers, road volume, number of traffic collisions, and non-traffic collisions, and total collision/road volume ratio. We also used these factors, along with demographic and economic factors, to determine whether an area was residential or commercial.

We chose these factors because they are common properties of all neighbourhoods and because they are relevant to determining why accidents occur in certain neighbourhoods. We also looked at common reasons thought to be responsible for accidents, such as age, gender and race. We analyzed the distribution of these factors among the neighbourhoods, and searched for correlations.

\section{Results}

Figure 1 compares all the relevant properties of each outlier, showing a contrast between the positive and negative outliers.

Figure 2 shows that not all neighbourhoods follow the trend line. This means there are factors other than road volume that determine the traffic safety of a neighbourhood 
Figure 1: Outlier neighbourhoods in Toronto when correlated with relevant factors; positive outliers are presumed safer and negative, more dangerous.

\begin{tabular}{|c|c|c|c|c|c|c|c|}
\hline $\begin{array}{c}\text { Negative } \\
\text { Outliers }\end{array}$ & $\begin{array}{c}\text { Area } \\
\text { Size } \\
\text { (in km²) }\end{array}$ & Population & $\begin{array}{c}\text { Number of } \\
\text { employees }\end{array}$ & $\begin{array}{c}\text { Road } \\
(\mathrm{km})\end{array}$ & $\begin{array}{c}\text { Road } \\
\text { Volume } \\
\text { Vehicles } \\
\text { (vehicles } \\
\text { per 24 } \\
\text { hours) }\end{array}$ & $\begin{array}{c}\text { Number } \\
\text { of total } \\
\text { collisions }\end{array}$ & $\begin{array}{c}\text { Collision } \\
\text { to Road } \\
\text { Volume } \\
\text { Ratio }\end{array}$ \\
\hline $\begin{array}{c}\text { West } \\
\text { Humber- } \\
\text { Clairville } \\
\text { (ID \#1) }\end{array}$ & 30.09 & 34,100 & 58,271 & 165 & 5956.63 & 1505 & 0.2527 \\
\hline $\begin{array}{c}\text { Yorkdale-Glen } \\
\text { Park } \\
\text { (ID \#31) }\end{array}$ & 5.9 & 14,685 & 24,685 & 49.71 & $4,193.75$ & 1253 & 0.2988 \\
\hline $\begin{array}{c}\text { Downsview } \\
\text { Roding- CFB } \\
\text { (ID \#26) }\end{array}$ & 14.9 & 34,650 & 20,150 & 87.99 & 2825.89 & 904 & 0.3199 \\
\hline $\begin{array}{c}\text { Positive } \\
\text { Outliers }\end{array}$ & 2.1 & 13,150 & 2,198 & 17.69 & $13,491.50$ & 123 & 0.0091 \\
\hline $\begin{array}{c}\text { Mount Dennis } \\
\text { (ID \#115) }\end{array}$ & 1.8 & 14,295 & 3,446 & 22.48 & $11,837.29$ & 230 & 0.0194 \\
\hline $\begin{array}{c}\text { Briar Hill- } \\
\text { Belgravia } \\
\text { (ID \#108) }\end{array}$ & 1.8 & 13,535 & 2,207 & 29.92 & 10,812 & 186 & 0.0172 \\
\hline $\begin{array}{c}\text { Bayview } \\
\text { Wods-Steeles } \\
\text { (ID \#49) }\end{array}$ & 4.1 & & & & & & \\
\hline
\end{tabular}

As it was mentioned earlier, this is one of the factors that was used to determine the outliers. Figure 3 shows both extremes of the collision to road volume ratio. The highlighted neighbourhoods are the outliers we chose based on both the graph (figure 2) and the table (figure 3).

Figure 4 and 5 are examples of the factors commonly thought to have a great effect on collision rates, but they show no correlations.

\section{Discussion}

From these results, we observe that the negative outliers are all major commercial areas, where most traffic is from people commuting to work or driving to shopping centres at specific peak times. Many people collecting into a single location raises the vehicle and pedestrian density, increasing the probability for a collision to occur. This behaviour is analogous to a funnel, where marbles at the edge are sparse and become dense as they move closer to the centre. This creates a bottleneck where accidents are far more likely to occur. It is difficult to maintain total awareness when there are many drivers, pedestrians and objects to avoid, so even if the driver is not distracted, they may have trouble tracking their surroundings simply because there is too much to consider. On the other hand, the positive outliers have a smaller road usage but high road volume. These neighbourhoods are also dense residential areas, with very few commercial zones within each. When compared relative to our negative outliers, these neighbourhoods are rather small. Drivers tend to not collect excessively in residential areas or drive continuously around residential areas throughout the day.

It was found that the demographic factors that are commonly thought to be factors in accidents, such as differences in gender or age distribution, are in fact not major factors in road safety. 
Total Collisions against Road Volume

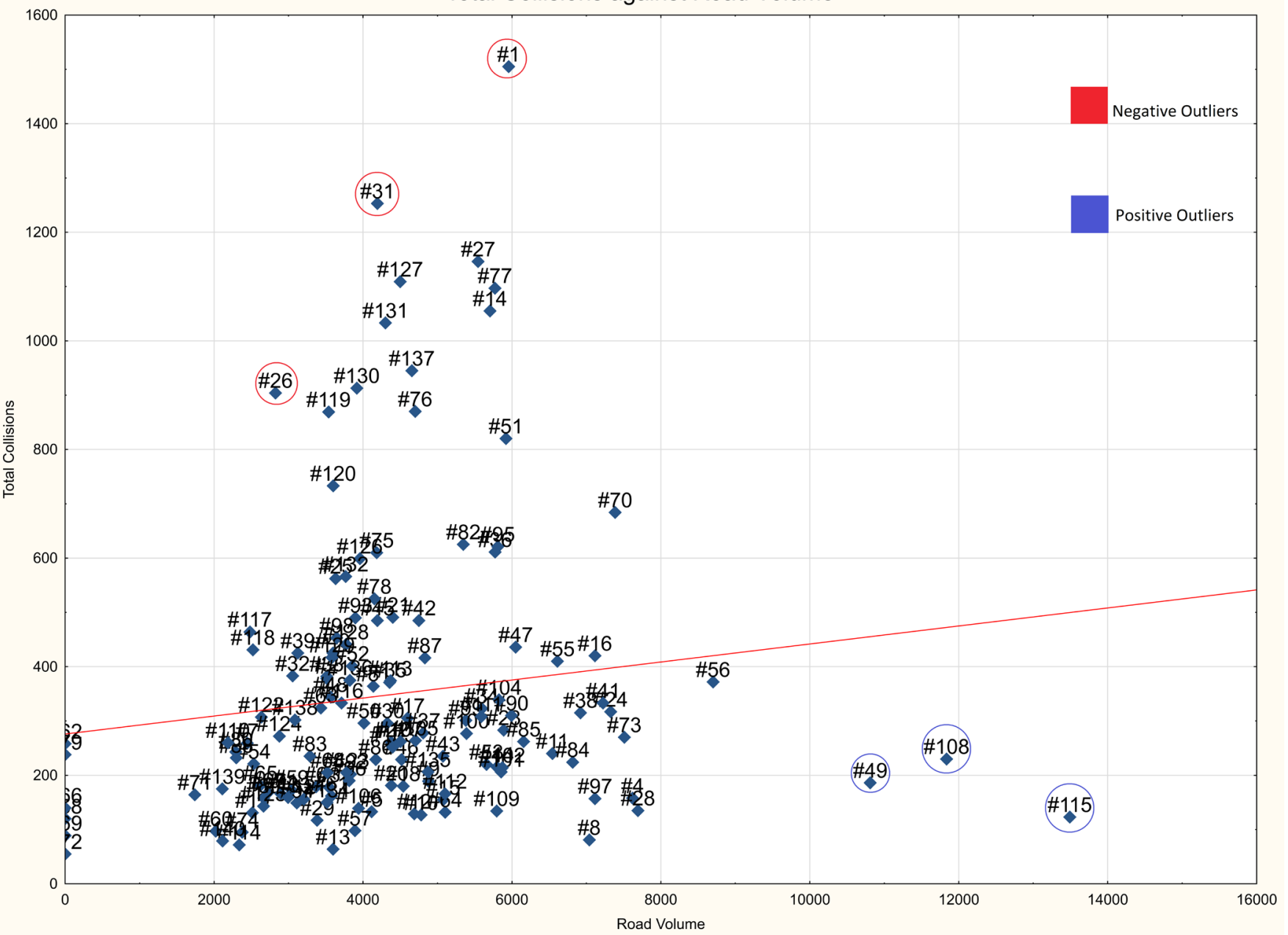

Figure 2: Total Collisions when correlated to Road volume.

\begin{tabular}{r|l|r|r|} 
& Neighbourhood & Neighbourhood Id & Ratio (Collison to road volume) \\
\hline 1 & Downsview-Roding-CFB & 26 & 0.319899343 \\
\hline 2 & Yorkdale-Glen Park & 31 & 0.298777943 \\
3 West Humber-Clairvil1e & 1 & 0.252659264 \\
\hline 4 & Bendale & 127 & 0.246492776 \\
\hline 5 & Wexford/Maryvale & 119 & 0.245532246 \\
\hline 6 & Rouge & 131 & 0.240181559 \\
\hline 7 & Milliken & 130 & 0.233052547 \\
\hline 8 & York University Heights & 27 & 0.206626099 \\
\hline 9 & Clairlea-Birchmount & 120 & 0.203554568 \\
\hline 121 & Kingsway South & 15 & 0.0305218247 \\
\hline 122 & Mark1and Wood & 12 & 0.0275092408 \\
\hline 123 & Princess-Rosethorn & 10 & 0.0265634804 \\
\hline 124 & Woodbine Corridor & 64 & 0.025862069 \\
\hline 125 & Broadview North & 57 & 0.0251798561 \\
\hline 126 & Caledonia-Fairbank & 109 & 0.0231193927 \\
\hline 127 & Yonge-St.Clair & 97 & 0.0220629567 \\
\hline 128 & Rexdale-Kinling & 4 & 0.0207312806 \\
\hline 129 & Briar Hi11-Belgravia & 108 & 0.01943013 \\
\hline 130 & Etobicoke West Mal1 & 13 & 0.0177876598 \\
\hline 131 & Rustic & 28 & 0.017550702 \\
\hline 32 & Baview Woods-Steeles & 49 & 0.0172031077 \\
\hline 133 & Humber Heights-Westmount & 8 & 0.0115073164 \\
\hline 34 & Mount Dennis & 115 & 0.00911685135 \\
\hline
\end{tabular}

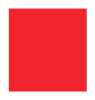

Negative

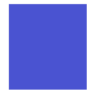

Positive

Average:

0.081

Figure 3: Positive and negative outliers of the collision to road volume ratio. 


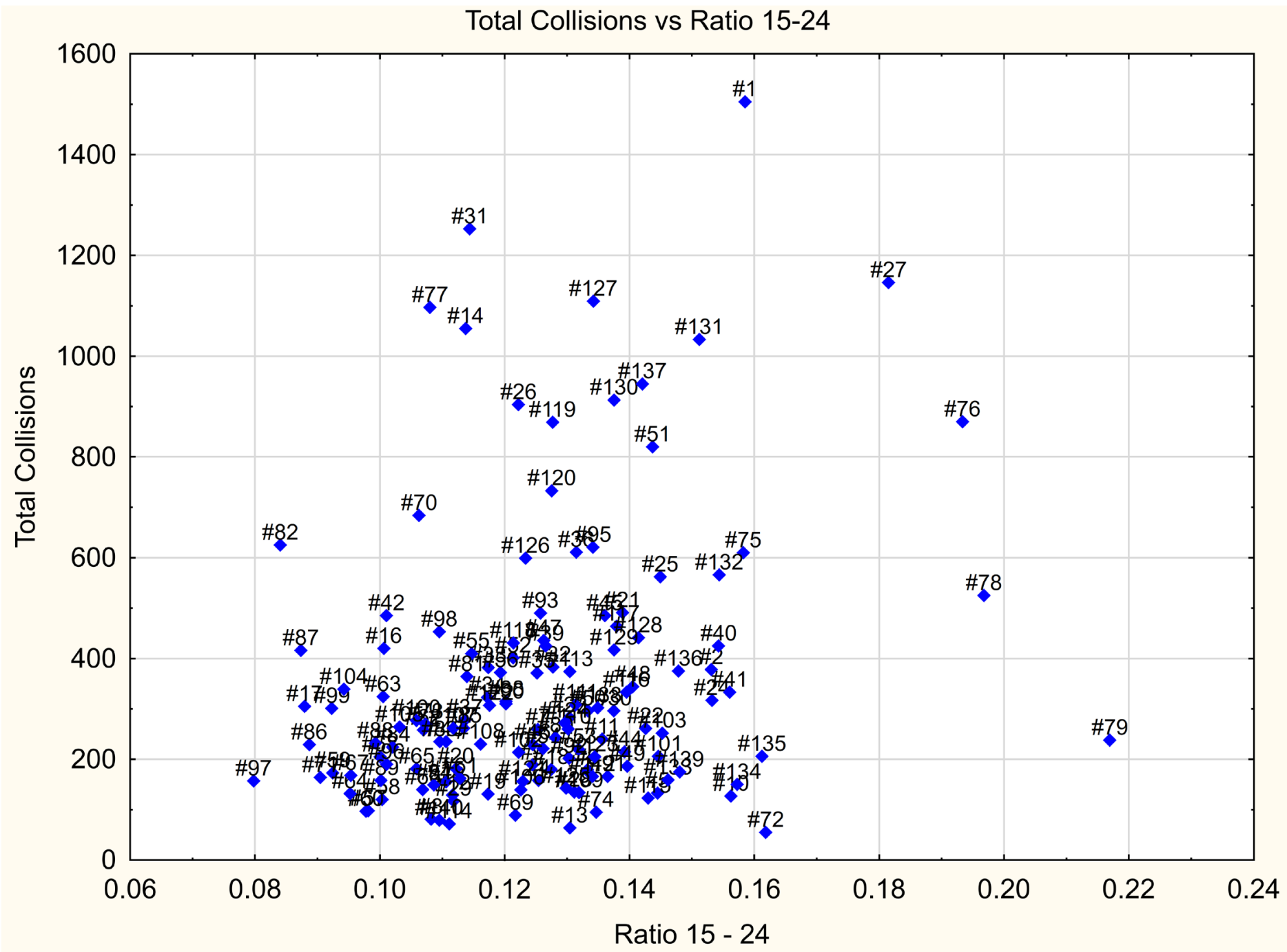

Figure 4: Total Collisions compared to Ratio of Youth in neighbourhood.

In most cases, this is because none of the neighbourhoods have major differences in their demographics. Gender had fairly equal distribution among all the neighbourhoods, and any differences in race and age were negligible. Graphing these, we found that there was no trend; the graphs tended to be very scattered. For example, among these graphs was Income vs Total Collisions (figure 5). Since most Torontonians make between $\$ 50,000$ and $\$ 100,000$ annually, the variance on the graph is only vertical within this small range, and thus we can gain no information from this graph. Anything outside of this range was also very scattered.

There are some uncertainties, or sources of error, in our analysis. The data we had access to was not entirely up to date, as the last census was in 2011. Some of the data was unavailable from the 2011 census, and it was substituted with data gathered in 2008 . We disregarded the 2008 data to keep everything as recent as possible. We do not know the exact methods used to gather the data, so we inherit whatever sources of error were present during the data collection. We would have liked to have more data, such as the nature of each accident, the speed limit of each neighbourhood, the speed of individual drivers, the age of ticketed drivers, how many pedestrian accidents were due to jaywalking or driving under the influence, the nature of accidents that were not reported and so on. This data either did not exist, or was inaccessible.

\section{Conclusion}

Businesses and commercial areas will inevitably centralize. However, the city can work around the negative effects of business and commercial centralization. Some conventional methods of slowing down traffic or preventing accidents by modifying rules have shown to have adverse effects. For example, pedestrians using crosswalks are generally less aware of oncoming traffic, and drivers may not notice that a pedestrian is crossing. Low speed limits are difficult to enforce and don't necessarily reduce the number of accidents, only the speeds at with which the accidents occur. This prevents fatali- 


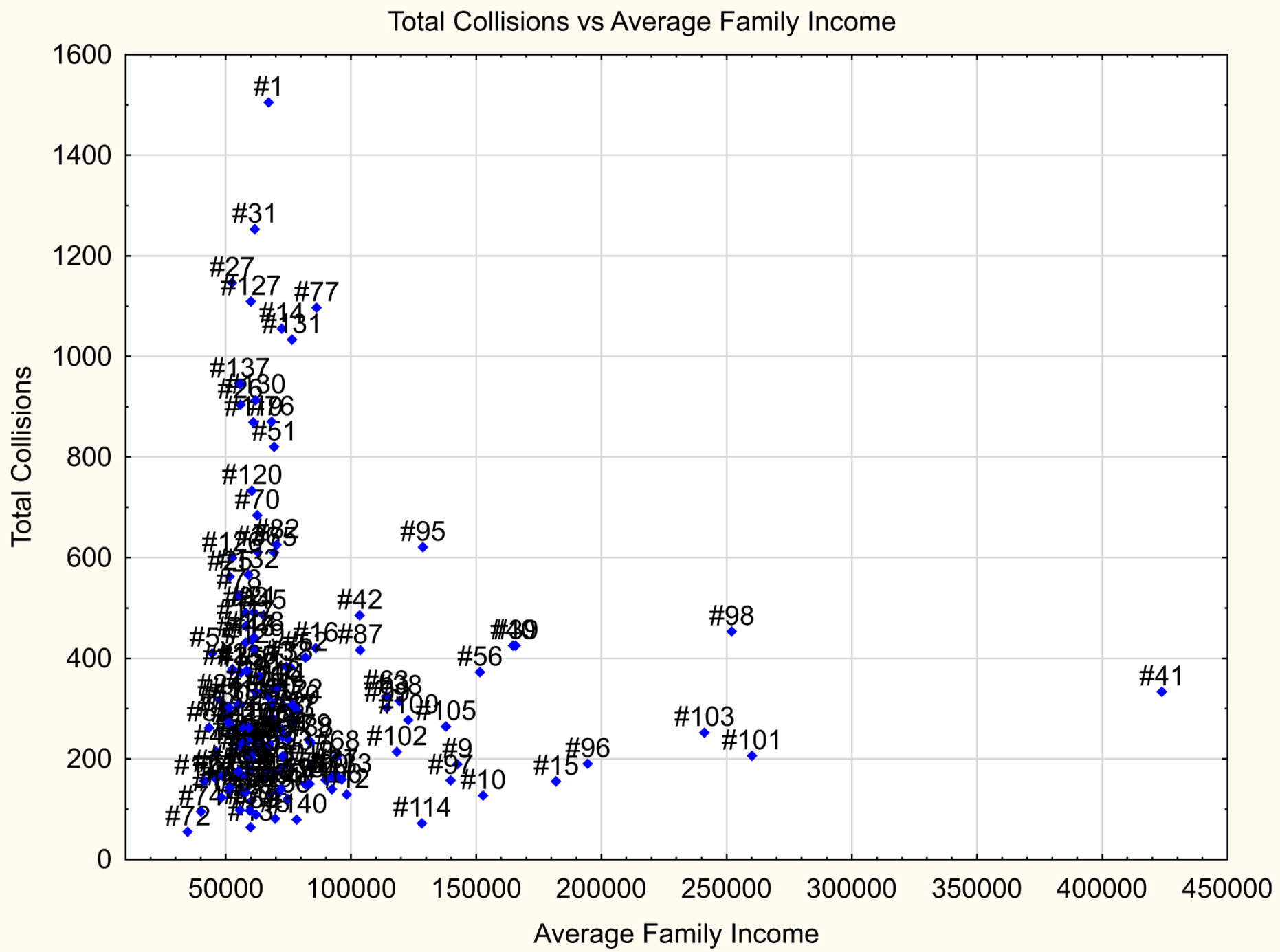

Figure 5: Total Collisions compared to Average Family Income in Neighbourhood.

ties, but if the limits are not likely to be followed and the number of accidents is unchanged, then this method is not entirely effective. One possible solution that can work parallel to others is changing the strategy used to market safe driving. In some cultures, like in Northern Europe, the consequences of unsafe driving are conveyed as damaging others, such as hurting another person. In other cultures, such as in the US, the consequences are conveyed as damaging one's self, such as guilt or a fine. Human error and human limitations are a major cause of accidents. Self-driving technology can eliminate the majority these issues, such as distractions, (difficulty being aware of everything), visibility during poor weather conditions, etc. Not only can self-driving technology eliminate these issues, it can go above and beyond human limitations, such as cars being able to communicate specific data about each car and the state of the roads to each other, having awareness of every car on the road and every pedestrian within a given radius, and so on.
Another solution would be Complete Streets. Complete Streets are roads that are designed to be used by all ages and abilities regardless of modes of transportation while maintaining a comfortable and safe environment. While Complete Streets have shown benefits, promoting driver awareness and making driving safer, the concept is still early in development and requires more research to finalize. What we identify as the core problem, the negative effects of centralizing business and commercial centres, cannot be changed, but it can be worked around using modern design philosophies such as Complete Streets, modified marketing of public safety, and advents in technology such as self-driving cars.

\section{Acknowledgement}

We would like to thank Dr. D. Stout and Dr. S. Noukhovitch for their assistance and mentorship over the course of this study. 


\section{References}

1. www1.toronto.ca. Wellbeing Toronto - Demographics - Data catalogue - Open Data | City of Toronto [Internet]. 2015 [cited 20 December 2015]. Available from: http://www1.toronto.ca/wps/portal/contentonly?vgnextoid=4482904ade9ea410VgnVCM10000071d60f89RCRD\&vgnextchannel=1a66e03bb8d1e310VgnV CM10000071d60f89RCRD

2. www1.toronto.ca. Wellbeing Toronto - Economics - Data catalogue - Open Data | City of Toronto [Internet]. 2015 [cited 20 December 2015]. Available from: http://www1.toronto.ca/wps/portal/contentonly?vgnextoid=aec380ece073b410VgnVCM10000071d60f89RCRD\&vgnextchannel=1a66e03bb8d1e310VgnVCM100 00071d60f89RCRD

3. www1.toronto.ca. Wellbeing Toronto - Transportation - Data catalogue - Open Data | City of Toronto [Internet]. 2015 [cited 20 December 2015 ]. Available from: http://www1.toronto.ca/wps/portal/contentonly?vgnextoid=e1ad842971e5a410VgnVCM10000071d60f89RCRD\&vgnextchannel=1a66e03bb8d1e310VgnV

CM10000071d60f89RCRD

\section{REVIEW}

by Keith McDonald, Open Data Lead, City of Toronto

I approach these comments, and my judging, as a communications person by trade vs. a data scientist. One of the issues in the information and technology milieu is poor communications.

There is a huge need for clear language and demonstrating a capacity to convey complicated messages, quickly, and in an understandable way.

While City of Toronto data sets aren't the only expectation of being used, I was looking for some explanation of how our data was used as the starting point and/or to augment other sources.

I am also mindful of the danger of using correlations to reflect hard conclusions. I wanted more detail in many cases that validate beyond just coincidence or surface level analysis. If you have seen the website Spurious Correlations (see: tylervigen.com) you will have seen how risky assumptions can be.

All-in- all, the quality of the ideas and the outcomes - especially provided that the students having started from a black hole of question marks, is very impressive! Congratulations to all for strong evidence of good old fashioned hard work. 